\title{
El proceso de institucionalización de la "Ley de Bosques" en la provincia de Buenos Aires, Argentina (2009-2016). Un análisis desde el marco del IAD*
}

The institutionalization process of the "Forest Law»

in Buenos Aires province, Argentina (2009-2016):

an analysis through the politicized IAD framework

\author{
PATRICIO HERNÁN STRACCIA** \\ Universidad de Buenos Aires, Argentina \\ Consejo Nacional de Investigaciones Científicas y Técnicas, Argentina \\ straccia@agro.uba.ar
}

https://doi.org/10.46468/rsaap.15.1.A2

\begin{abstract}
Resumen: En este artículo analizamos el proceso de institucionalización de la "Ley de Bosques" en la provincia de Buenos Aires, Argentina (2009-2016). Se trata de una política pública en materia ambiental que regula las formas de uso y apropiación de los bosques nativos de la provincia. Desde el marco del análisis y desarrollo institucional (IAD) "politizado", identificamos y caracterizamos las arenas de acción constituidas a nivel operacional y a nivel decisional, analizando la situación de acción y los actores participantes en ella. Los datos fueron producidos a través del enfoque etnográfico, mediante entrevistas semiestructuradas y en profundidad con los distintos actores sociales, complementado con un análisis documental de fuentes secundarias. A través de nuestro recorrido, mostramos cómo se constituyen múltiples arenas de acción en la producción de políticas públicas ambientales, evidenciamos que la política pública producida es el resultado de disputas y negociaciones entre actores estatales y no estatales que buscan acceder a los espacios de toma de decisión en pos de intereses específicos, y resaltamos algunas de las formas a través de las cuales se producen las estatalidades.
\end{abstract}

Palabras Clave: "Ley de Bosques" - IAD - Buenos Aires - Delta del Paraná - Estructura de oportunidades políticas

\begin{abstract}
In this article we analyze the institutionalization process of the «Forest Law « in the province of Buenos Aires, Argentina (2009-2016). It is a public policy that regulates the forms of use and appropriation of the native forests of the province. Through the politicized IAD framework, we identify and characterize the action arenas constituted at the operational level and at the decisional level, analyzing the action situation and the actors participating in it. Data were produced through the ethnographic approach (semi-structured and in-depth interviews with the different social actors), complemented by a documentary analysis of secondary sources. We present evidence of the ways multiple action arenas are constituted in the production of environmental public policies, we show that public policies are the result of disputes and negotiations between state and non-state actors that seek access to decision-making spaces in pursuit of specific interests, and we highlight some of the ways in which statehoods are produced.
\end{abstract}

Key Words: Forest Law - IAD - Buenos Aires - Delta del Paraná - Political Opportunity Structure

* Artículo recibido el 23 de diciembre de 2019 y aceptado para su publicación el 12 de marzo de 2021.

** El autor agradece el aporte de evaluaciones anónimas a una versión previa de este artículo y también a Fernando Jaime por sus aportes en el marco de un seminario doctoral. 


\section{Introducción ${ }^{1}$}

En las últimas décadas, las teorías incrementales y las perspectivas procesualistas permitieron incorporar nuevas dimensiones de análisis al estudio de las políticas públicas (Aguilar Villanueva, 1992; Subirats et al., 2008). Las investigaciones ya no se focalizaron únicamente en la etapa de implementación sino que comenzaron a incluir a los procedimientos y estrategias llevadas a cabo por los actores estatales y no estatales a lo largo de todo el proceso de la política (Aguilar Villanueva, 1996; Cowan Ros, 2016). Esto requiere considerar la singularidad de los contextos sociales e históricos en los cuales se desarrollan. Al respecto, autores del campo de la antropología política postularon que las políticas públicas se constituyen como un campo de lucha entre distintos actores y señalaron la importancia de analizar qué es lo que está en disputa en cada instancia de (re)producción de la política (Shore y Wright, 1997; Wedel et al., 2005).

Siguiendo a Escolar (2010), las instituciones representan un espacio de producción y reproducción de las relaciones sociales de producción. El análisis de los procesos de institucionalización, por lo tanto, hace foco en el enfrentamiento entre lo dado y las resistencias a lo dado (Escolar, 2000). En este artículo, el concepto institucionalización remite a lo planteado por Ostrom (2005) y Portes (2006): se trata de un proceso de formación de instituciones, siendo éstas los conjuntos de reglas/prescripciones que gobiernan las relaciones entre los actores. En relación con las cuestiones ambientales, la importancia de la mirada centrada en la disputa en torno a los procesos de institucionalización ha sido señalada por Melé (2003), Piermattei (2013) y Merlinsky (2013), entre muchos otros.

En Argentina, la institucionalización de la cuestión ambiental ha sido un proceso errático y carente de una dirección consistente a lo largo del tiempo (Díaz, 2006; Gutiérrez e Isuani, 2013 y 2014). Uno de los principales instrumentos para establecer reglas que favorecieran la conservación del ambiente han sido las leyes de presupuestos mínimos de protección ambiental, enmarcadas en las facultades delegadas por las provincias a la Nación luego de la reforma constitucional de 1994 a través del art. 41 de la Constitución Nacional (CN). Aun cuando las provincias detentan el dominio originario de sus recursos naturales (según el art. $124 \mathrm{CN}$ ), éstas ceden a la Nación la capacidad de generar normas que concedan una tutela ambiental uniforme para todo el país con el objeto de imponer las condiciones necesarias para asegurar la protección ambiental (Esain, 2004).

Esta investigación fue realizada en el marco de dos proyectos financiados por la Universidad de Buenos Aires (20020130100147BA y 20020170100492BA). 
A partir de estos lineamientos, en la última década la política ambiental de nuestro país se ha expresado mayormente a través de la sanción de leyes de presupuestos mínimos que regulan las formas de uso y apropiación del ambiente en diferentes tipos de ecosistemas. Una de las primeras en ser sancionada fue la Ley General del Ambiente, que oficia como ley marco y define los objetivos, los principios y los instrumentos de la política ambiental nacional. Cada una de las restantes leyes de presupuestos mínimos sancionadas posteriormente busca regular dimensiones específicas del dominio de lo ambiental, como los bosques, los glaciares y el ambiente periglacial, o los humedales ${ }^{2}$. Sin embargo, la producción de leyes de presupuestos mínimos es un proceso eminentemente conflictivo, como todos los espacios sociopolíticos en los que se dirimen las políticas públicas. Y es que, como señala Roig (2008), la supresión del conflicto no es ni teórica ni políticamente alcanzable, y su carácter inmanente nos obliga a pensar a las instituciones que regulan las sociedades como conflictos estabilizados.

Este artículo se focaliza en la génesis de una política pública ambiental en particular (Müller, 2000) y analiza el proceso de institucionalización de la "Ley de Bosques" en la provincia de Buenos Aires, Argentina (2009-2016). Esto es, se analiza el proceso de institucionalización de la norma provincial complementaria de la Ley Nacional 26.331 de Presupuestos Mínimos de Protección Ambiental de los Bosques Nativos (aprobada en 2007), la cual debía ser sancionada por el Poder Legislativo de la provincia de Buenos Aires. Esta provincia, que también ha tenido un comportamiento errático en lo referido a la institucionalización ambiental (Isuani, 2013), fue la que mayor demora tuvo en la sanción de esta norma en todo el país (MAyDS, 2016).

\section{Antecedentes y Caracterización de la LN 26.331}

La Ley 26.331 de Presupuestos Mínimos de Protección Ambiental de los Bosques Nativos fue sancionada por el Congreso de la Nación a fines del año 2007. Se trata de una ley que establece la obligatoriedad para cada pro-

En el año 2002 se sancionó la Ley General del Ambiente (LN 25.675), que define los presupuestos mínimos para la gestión sustentable del ambiente. Luego se sancionaron leyes específicas, como la Ley de Presupuestos Mínimos de Protección Ambiental de los Bosques Nativos (LN 26.331) en el 2007 o el Régimen de Presupuestos Mínimos para la Preservación de los Glaciares y el Ambiente Periglacial (LN 26.639) en el 2010, entre otras. La posibilidad de sancionar una Ley de Presupuestos Mínimos para la protección de los humedales está en debate desde el 2010, pero hasta el momento los intentos no han sido exitosos (Straccia, 2019). 
vincia de producir un Ordenamiento Territorial de los Bosques Nativos (de aquí en adelante, OTBN). Cada provincia debía inicialmente construir un inventario de sus bosques nativos, y posteriormente categorizarlos de acuerdo con los lineamientos definidos por la Ley nacional. Finalmente, el OTBN debía ser sancionado a través de una ley provincial, y luego homologado por la autoridad nacional de aplicación (la Secretaría/Ministerio de Ambiente y Desarrollo Sustentable de la Nación).

Para llevar adelante este proceso, cada una de las áreas de bosques inventariadas debía ser categorizada en uno de los tres niveles de conservación definidos en la Ley Nacional. Las zonas rojas son definidas como áreas de alto valor de conservación e imposibilidad de transformación; las zonas amarillas son áreas de mediano valor de conservación, susceptibles de ser sometidas a un aprovechamiento sostenible; finalmente, las zonas verdes son áreas de bajo valor de conservación y por tanto con pocas restricciones para el desarrollo de actividades productivas. Esta zonificación debía realizarse siguiendo diez criterios específicos de sustentabilidad definidos en la Ley, aunque, como lo evidencian García Collazo et al. (2013) y Gautreau et al. (2014), éstos no fueron tenidos en cuenta en muchos de los procesos de construcción de los ordenamientos provinciales.

La Ley contenía prerrogativas restrictivas, dado que los artículos 7 y 8 prohibían la autorización de desmontes y todo tipo de aprovechamiento de los bosques nativos provinciales hasta tanto el OTBN no fuera realizado. Sin embargo, también se desarrollaron instrumentos de estímulo novedosos en el marco de políticas ambientales, como la constitución de un Fondo para el Enriquecimiento y Conservación de los Bosques Nativos, al cual podrían acceder tanto los titulares de las tierras como las provincias, una vez sancionada la ley provincial correspondiente ${ }^{3}$. A través de este tipo de incentivos se buscaba evitar que la Ley tuviera un carácter meramente restrictivo, y brindar herramientas alternativas económicas para los titulares de tierras que fueran inventariadas y categorizadas en este marco.

Diversos investigadores han estudiado múltiples dimensiones vinculadas a esta temática. Sin embargo, en líneas generales, los estudios se focalizaron en una etapa específica del proceso de la política. En la mayor parte de los casos, se concentraron en comprender etnográficamente el proceso de producción de los ordenamientos en cada una de las provincias, como en Salta (Schmidt, 2014) o en Córdoba (Silvetti et al., 2013; Vera, 2015) entre otras, aunque no

El $70 \%$ de dicho Fondo estaría destinado a los titulares de las tierras que realizaran prácticas de conservación o enriquecimiento de sus bosques nativos, mientras que el $30 \%$ se destinaría a las provincias para fortalecer a las autoridades provinciales de aplicación de la Ley. 
hemos encontrado hasta la fecha estudios que se hayan focalizado en la producción del OTBN en Buenos Aires. En otros casos, el foco estuvo puesto en la construcción del problema a nivel nacional (Langbehn, 2016), en el análisis de sus implicancias (Stecher, 2013) o en análisis comparativos de su implementación en distintas provincias (García Collazo et al., 2013; Gautreau et al., 2014). Incluso algunos autores, a partir de su evaluación, han presentado propuestas concretas para mejorar la política pública (Aguiar et al., 2018). En líneas generales, lo que se observa es que las investigaciones hicieron énfasis en un nivel en particular para llevar adelante el análisis. El estudio de Gutiérrez (2017) es una clara excepción a este patrón, puesto que reconoce el carácter multinivel de las coaliciones Sociedad-Estado que se conforman y señala su capacidad de incidir en la formulación de las políticas de protección de los bosques nativos tanto a nivel nacional como provincial, a través de un detallado recorrido sobre sus formas de operar en ambos niveles.

Esta investigación, que apela a las técnicas etnográficas de producción de datos, también se asienta sobre un marco conceptual que permite el análisis multinivel. Sin embargo, por las características singulares del proceso de formulación de la "Ley de Bosques" en la provincia de Buenos Aires, considero que el enfoque que propone la oposición entre una coalición vinculada con la expansión agropecuaria y otra vinculada con la protección de los bosques nativos representa un corsé que limita nuestra capacidad analítica para comprender por qué los actores sociales actuaron de la forma en que lo hicieron y para captar las singularidades del proceso de producción de esta política ${ }^{4}$. Por lo tanto, activamos las categorías del enfoque institucional y, más específicamente, de una versión adaptada del IAD (Ostrom 2005 y 2007), llamada IAD "politizado" (Clement, 2010), a fin de dar cuenta de las formas en que se constituyeron las distintas arenas de acción y los modos en que éstas se vincularon en el caso particular de la provincia de Buenos Aires.

\section{Estrategia teórico-metodológica}

Para poder analizar el proceso de institucionalización de la "Ley de Bosques" en la provincia de Buenos Aires, retomamos los elementos del

Vale aquí una aclaración, y es que el enfoque de las coaliciones propuesto por Gutiérrez (2017) ha demostrado sobradamente ser adecuado para analizar los conflictos en torno a la producción de políticas públicas en materia ambiental. Sin embargo, al momento de interpelar mi objeto de estudio, un análisis preliminar desde ese marco conceptual evidenció la existencia de algunas limitaciones, y por eso es que en este artículo propongo trabajar desde otro marco. 
marco del análisis y desarrollo institucional (IAD). Este marco conceptual constituye una perspectiva basada en el actor sin perder de vista la importancia de los arreglos institucionales (Ostrom, 2005 y 2007). Los individuos, bajo este enfoque, son considerados actores racionales que operan en diferentes entornos institucionales, los cuales influyen en sus comportamientos estratégicos (Jaime et al., 2013).

Inicialmente, el IAD requiere la identificación de las arenas de acción, esto es, los espacios sociales en los que los individuos interactúan, intercambian, cooperan y disputan entre sí (Ostrom, 2007). Las arenas de acción, en tanto unidad conceptual, presentan dos elementos constituyentes: a) la situación de acción; y b) los actores individuales y colectivos participantes en esa situación. La Tabla 1 sintetiza los siete elementos descriptores de las arenas de acción.

A su vez, cada arena de acción está atravesada por diferentes variables exógenas (también llamadas "factores contextuales"). El marco original del IAD refiere a tres tipos de variables: las variables biofísicas, los atributos de la comunidad y las reglas (Araral y Amri, 2016). Sin embargo, varios investigadores cuestionaron que estos factores contextuales no eran lo suficientemente históricos y políticos y no permitían dar cuenta de la operatoria de múltiples mecanismos de poder, por lo que se ha propuesto incluir dos variables exógenas adicionales para superar esta limitación: contexto político-económico y discursos (Clement, 2010). Estas cinco variables exógenas y sus respectivas definiciones también están sintetizadas en la Tabla 1. La Figura 1, por su parte, sintetiza los elementos conceptuales del IAD “politizado", siguiendo la definición de Clement (2010).

Complementariamente, el marco del IAD puede interpretarse como un mapa conceptual de múltiples niveles. Específicamente, siguiendo a Ostrom (2007), las arenas de acción pueden constituirse en cuatro niveles distintos: el nivel operacional (o instrumental), el nivel decisional (esto es, la toma de decisión a nivel gubernamental), el nivel constitucional (el conjunto de decisiones corporizados en marcos regulatorios) y el nivel metaconstitucional (Tabla 2). Por lo tanto, aquello que en un nivel es un sistema de acción en su totalidad, en otro nivel se constituye únicamente como una parte del mismo, y las reglas que ordenan la acción en un nivel dado (en carácter de variables exógenas) se definen en un nivel superior (Ostrom, 2005). De este modo, es posible analizar las formas de producción de políticas públicas en múltiples niveles dentro de un único marco conceptual, a partir de una adecuada caracterización de los elementos descriptores de las múltiples arenas de acción constituidas en cada momento del proceso. 


\section{FIGURA 1}

\section{Elementos conceptuales del IAD adaptado}

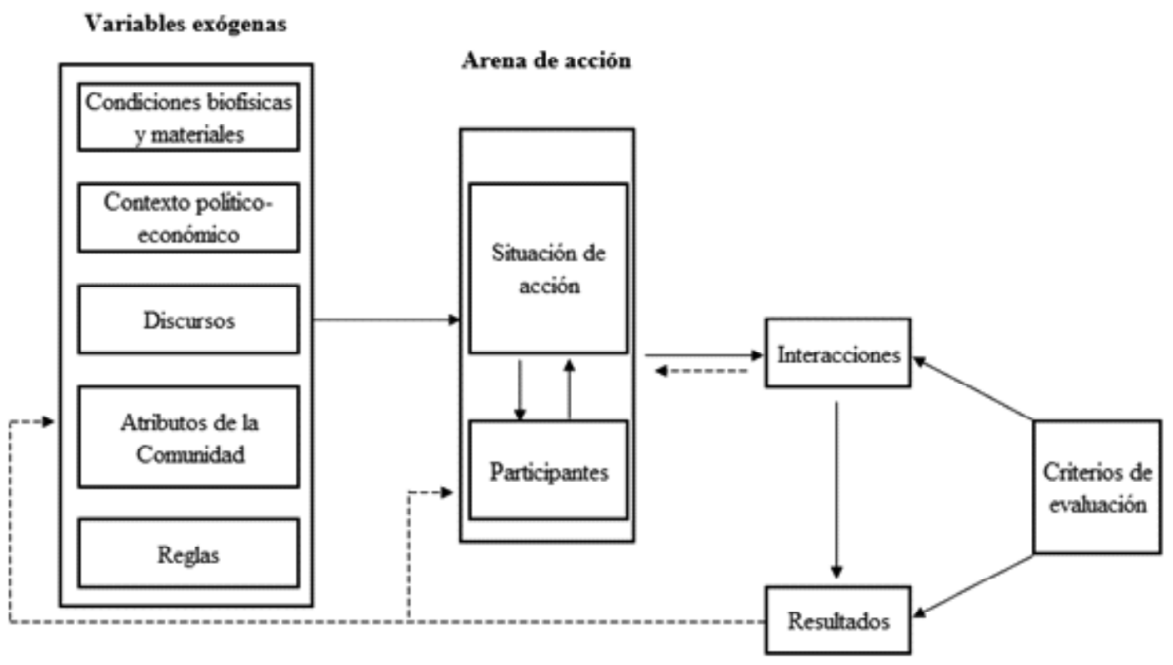

Fuente: Elaboración propia, adaptada a partir de Ostrom (2007) y Clement (2010).

Arenas de acción: elementos descriptores

(1) El conjunto de participantes

(2) Las posiciones específicas a ser ocupadas por los participantes

(3) El conjunto de acciones permitidas y su conexión con los resultados

(4) Los resultados potenciales que están vinculados a secuencias de acciones individuales

(5) El nivel de control que cada participante tiene sobre la elección

(6) La información disponible para los participantes sobre la estructura de la situación de acción

(7) Los costos y beneficios, que sirven de incentivo y disuasión, asignados a las acciones y a los resultados

\section{Variables exógenas: elementos descriptores}

(1) Las condiciones biofísicas y materiales refieren a los atributos de los recursos, las condiciones de los ecosistemas y sus transformaciones

(2) Los atributos de la comunidad (físicos y culturales) refieren al grado de entendimiento común que los participantes potenciales comparten sobre la estructura de la arena de acción o la distribución de los recursos entre los afectados

(3) Las reglas son las prescripciones compartidas entre los involucrados, referidas a qué acciones son requeridas, prohibidas o permitidas

(4) El contexto político-económico permite comprender cómo se distribuye el poder entre los actores participantes y cómo los intereses políticos y económicos movilizan sus acciones

(5) La consideración de los discursos resalta el carácter socialmente construido de la realidad y posibilita una mejor articulación con los postulados postestructuralistas que muestran la interrelación discurso/instituciones/poder

Fuente: Elaboración propia, a partir de Ostrom (2007), Clement (2010), Whaley y Weatherhead (2014) y Araral y Amri (2016). 


\section{TABLA 2}

Síntesis de los niveles de análisis ${ }^{5}$

\begin{tabular}{|l|l|}
\hline Niveles de Análisis & Síntesis \\
\hline $\begin{array}{l}\text { Nivel } \\
\text { metaconstitucional }\end{array}$ & $\begin{array}{l}\text { Refiere a las acciones de los individuos que afectan } \\
\text { las reglas que afectan las situaciones } \\
\text { constitucionales. }\end{array}$ \\
\hline Nivel constitucional & $\begin{array}{l}\text { Refiere a las acciones de los individuos que afectan } \\
\text { las reglas que afectan las situaciones decisionales. } \\
\text { Están vinculadas con formular, prescribir, y } \\
\text { adjudicar. }\end{array}$ \\
\hline Nivel decisional & $\begin{array}{l}\text { Refiere a las acciones de los individuos que afectan } \\
\text { las reglas que afectan las situaciones operacionales. } \\
\text { Están vinculadas con prescribir, gestionar, } \\
\text { monitorear, aplicar y hacer cumplir. }\end{array}$ \\
\hline Nivel operacional & $\begin{array}{l}\text { Refiere a las acciones de los individuos que afectan } \\
\text { directamente las condiciones biofísicas y materiales. } \\
\text { Están vinculadas con la provisión, producción, } \\
\text { distribución, apropiación, asignación y consumo de } \\
\text { los recursos. }\end{array}$ \\
\hline
\end{tabular}

Fuente: Elaboración propia, adaptada a partir de Ostrom (2007).

En esta investigación, de tipo cualitativa (Silverman, 2000; Mason, 2002), el análisis se realizó a partir de datos primarios producidos desde un enfoque etnográfico (Hammersley Y Atkinson, 2007). Entre los años 2012 y 2018 hemos realizado, junto con otros miembros del equipo de investigación, entrevistas semiestructuradas (Taylor Y Bogdan, 1996; Guber, 2001) con funcionarios y técnicos de instituciones ambientales, de desarrollo rural y de promoción de la forestación. Dado que este artículo está focalizado en los conflictos en la región del Delta Bonaerense del Paraná (tal como señalaremos en el próximo apartado), también hemos realizado entrevistas semiestructuradas con funcionarios y técnicos de agencias estatales que articulan las políticas vinculadas con el mismo, así como con representantes de asociaciones de productores familiares empresariales y empresas agroindustriales de la región. Además, hemos realizado entrevistas en profundidad (Taylor y Bogdan, 1996; Guber, 2001) e informales (Penalva Verdú et al., 2015) con productores y pobladores de la zona ${ }^{6}$.

En negrita se indica cuáles son los niveles de análisis activados en esta investigación.

Una descripción detallada del número de entrevistas y las adscripciones de los entrevistados están incluidas al final del artículo, dentro del apartado "Anexo Metodológico". 
El muestreo realizado fue de tipo cualitativo no probabilístico, combinando un muestreo de oportunidad a través de la técnica de la bola de nieve con un muestreo evaluado (Guber, 2001). Este tipo de muestreo sistematiza las variables individualizadas por el investigador a través de los informantes de oportunidad, de modo que se constituye a partir de criterios que surgen como significativos de los propios informantes. Las entrevistas se complementaron con instancias de observación participante (Taylor y Bogdan, 1996; Guber, 2001; Hammersley y Atkinson, 2007) en audiencias abiertas, reuniones realizadas por diferentes agencias estatales, y festividades locales, entre otros espacios ${ }^{7}$.

Por otra parte, también realizamos un análisis documental de diversas fuentes secundarias. Entre ellas se incluyen el texto correspondiente a la ley bajo estudio, actas de audiencias públicas, noticias publicadas en periódicos regionales, comunicados de asociaciones locales y documentos construidos por distintas agencias estatales en diferentes instancias del proceso de institucionalización de la "Ley de Bosques". Todos los registros producidos, provenientes tanto de fuentes primarias como secundarias, fueron posteriormente codificados a través del Atlas.Ti, un software diseñado específicamente para trabajar con este tipo de registros (Penalva Verdú et al., 2015).

\section{El proceso de institucionalización de la "Ley de Bosques" en la provincia de Buenos Aires}

En Buenos Aires, la autoridad de aplicación en materia ambiental es el Organismo Provincial para el Desarrollo Sostenible (de aquí en adelante, OPDS). Al interior del organismo, la Dirección Provincial de Recursos Naturales fue la agencia estatal encargada de la construcción de las líneas de base que permitieran primero inventariar y luego zonificar los bosques nativos de la provincia. Sin embargo, de acuerdo con los actores participantes en el proceso -y en línea con lo planteado por Juliá (2010) sobre las limitaciones técnicas y económicas de las autoridades provinciales de aplicación-, la Dirección carecía de los recursos técnicos y humanos necesarios para poder llevar adelante el proceso por sí misma. Además, la información preexistente sobre los bosques nativos provinciales se limitaba a las ecorregiones Espinal y Monte (SAyDS, 2005), y se desconocía qué proporción de bosques nativos

En el Anexo Metodológico se encuentra también una descripción detallada de cuáles fueron estos espacios. 
existían en el resto del territorio provincial o en qué estado de conservación se encontraban.

Para construir las líneas de base, la autoridad de aplicación decidió zonificar la provincia en cuatro regiones: Delta y Talares de Barranca, Bosque Ribereño, Talares del Este, y Cardenal y Monte (OPDS, 2013). Además, definió que se llevarían adelante procesos de articulación con referentes técnicos específicos para cada una de las cuatro regiones. Así, se constituyó un subsistema de políticas con una dimensión sustantiva y una territorial (Sabatier, 1991; Sabatier y Weible, 2010).

Retomando el marco de los niveles de análisis del IAD (Tabla 2), la Ley Nacional 26.331 de Protección Ambiental de los Bosques Nativos definía las reglas por intermedio de las cuales las autoridades provinciales podrían construir los OTBN, de modo que podría vincularse con el nivel constitucional. La toma de decisión a nivel provincial, esto es, el proceso de producción de la "Ley de Bosques", implicaba la constitución de una arena de acción a nivel decisional. A su vez, la construcción del OTBN propiamente dicho (que, en tanto zonificación, implica formas de uso y apropiación del ambiente) implicaba la constitución de una arena de acción a nivel operacional. Dado que el OTBN de la provincia de Buenos Aires se realizó por separado para cada una de las cuatro regiones previamente señaladas, se puede afirmar que se constituyeron cuatro arenas de acción simultáneas en el nivel operacional.

Por lo tanto, en este artículo analizamos, en primer lugar, la arena de acción constituida a nivel operacional en relación con la producción del OTBN en la primera región, Delta y Talares de Barranca, a partir de los elementos presentados en la Figura 1 y la Tabla 1. Y, posteriormente, analizamos la arena de acción constituida a nivel decisional en relación con la sanción de la "Ley de Bosques", a partir de esos mismos elementos. De este modo, se muestra que la política pública es el resultado de disputas y negociaciones entre actores estatales y no estatales, y se resaltan algunas de las formas a través de las cuales se producen las estatalidades (Cowan Ros, 2016).

\section{El nivel operacional: la construcción del OTBN en la región Delta y Talares de Barranca}

La región Delta y Talares de Barranca comprendía un área rural de más de 200.000 hectáreas, compuesta mayormente por islas atravesadas por cursos de agua donde las inundaciones periódicas moldean las prácticas productivas y de vida de los habitantes locales (Astelarra y Domínguez, 2015; Pizarro y Ortiz, 2019). Dentro de esta región se incluía a la totalidad del Delta Bonaerense del Río Paraná, constituida por los partidos de San Nico- 
lás, Ramallo, San Pedro, Baradero, Zárate, Campana, Tigre, San Fernando y Escobar (Figuras 2 y 3), así como a las zonas de Talares que se encontraban en la margen opuesta (continental) del río Paraná de las Palmas (OPDS, 2011).

\section{FIGURA 2}

El Delta del río Paraná. En la parte inferior se ubica la porción Bonaerense del Delta

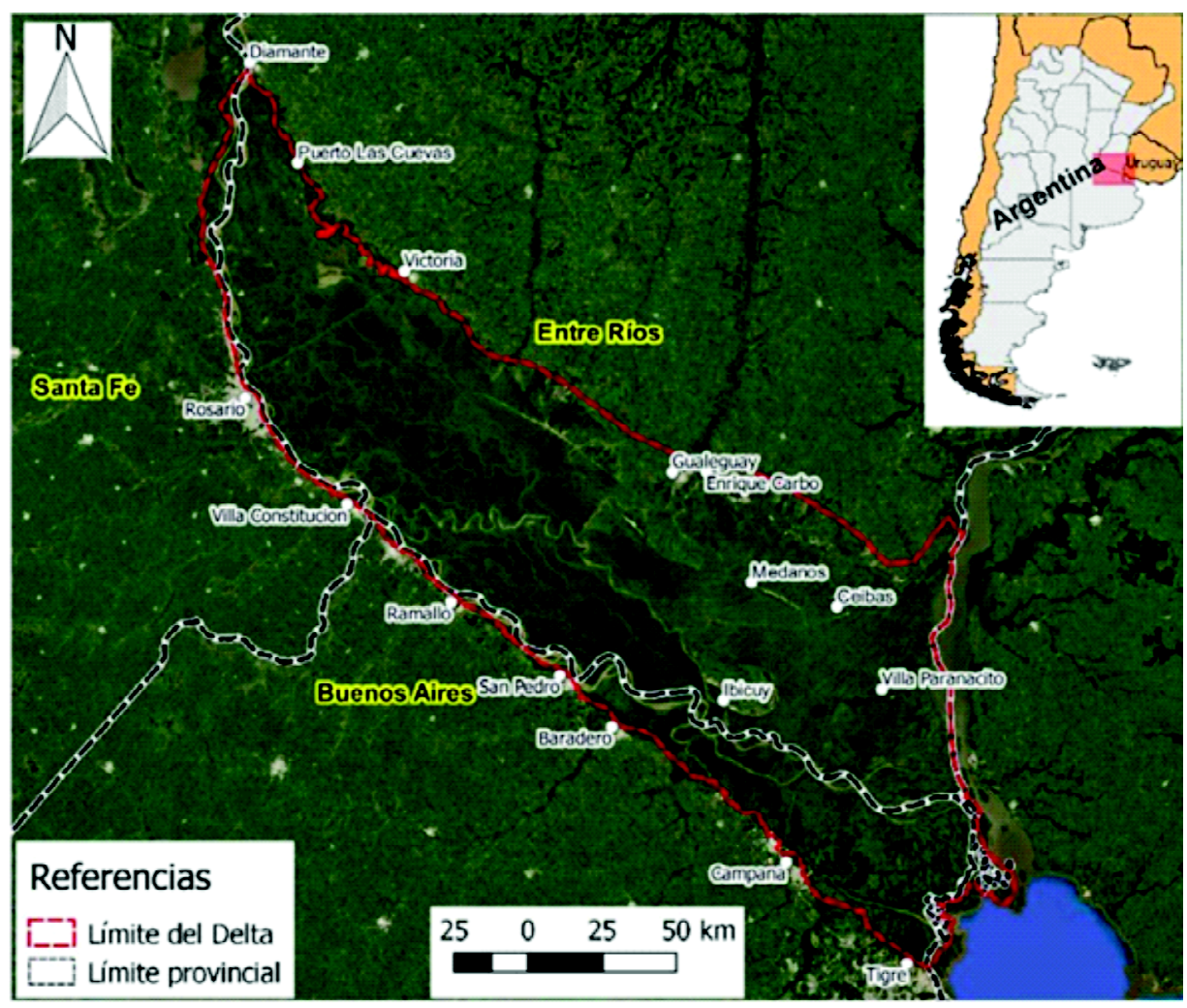

Fuente: Instituto Nacional del Agua (INA) (2018). 


\section{FIGURA 3}

División político-administrativa (en partidos) del Delta Bonaerense del río Paraná

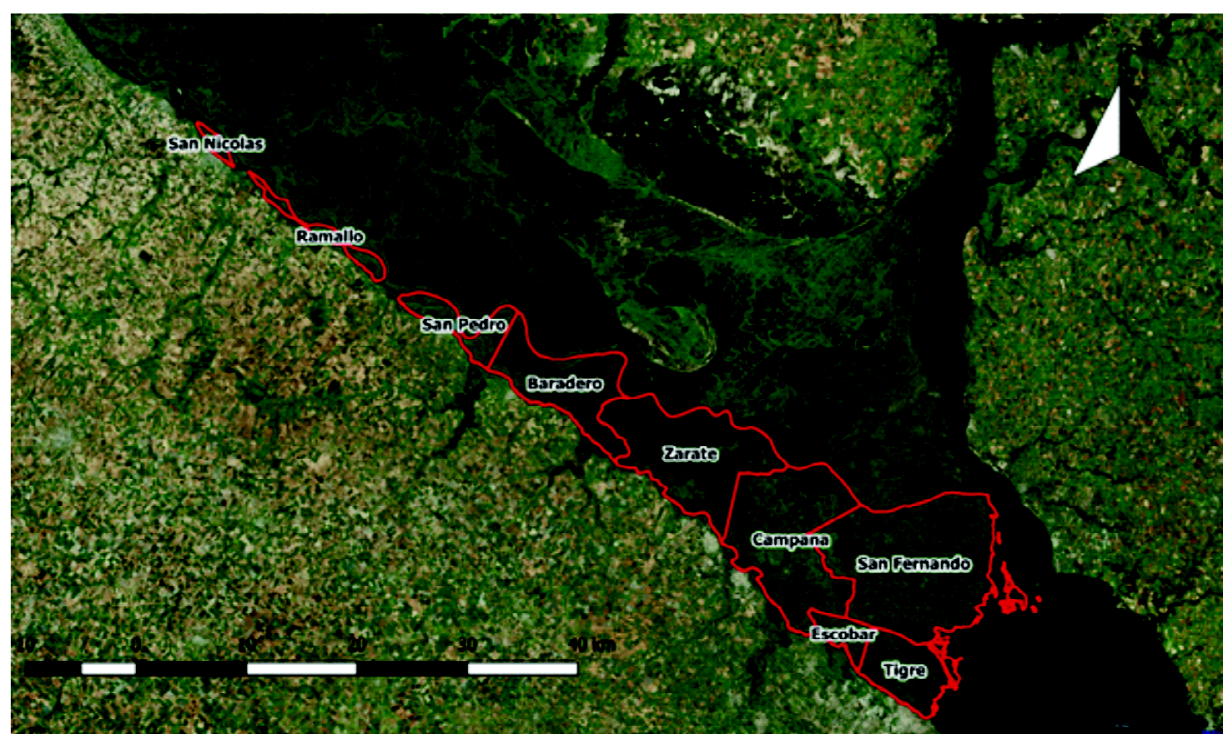

Fuente: Elaboración Propia.

Aunque con algunas características en común, especialmente en términos ecológicos, esta región presenta una gran heterogeneidad en términos de su matriz socio-productiva. En ciertas áreas del partido de San Fernando la producción mimbrera persiste dentro de un área definida como Reserva de Biósfera del Programa MaB-UNESCO (Olemberg y Barán, 2017), mientras que en Tigre el avance de los megaemprendimientos inmobiliarios han desplazado a los junqueros tradicionales de la zona y propiciaron grandes alteraciones en el paisaje (Astelarra y Domínguez, 2015). En las porciones superiores del Delta Bonaerense del Paraná, la ganadería, la pesquería e incluso la agricultura son las actividades productivas predominantes (Baigún, 2013; Quintana et al., 2014). Hacia la parte central de esta región, en los partidos de Campana y parte de San Fernando, la consolidación de la actividad forestal en la segunda mitad del siglo XX favoreció la conformación del polo forestal de salicáceas (álamos y sauces) más grande del país (Moreira, 2018). En esta zona, denominada Núcleo Forestal, coexisten empresas foresto industriales, productores familiares empresariales, productores familiares capitalizados y pequeños productores familiares (Pizarro, 2016). 
En las etapas iniciales de la construcción del OTBN para la región Delta y Talares de Barranca, siguiendo las prescripciones definidas en el nivel inmediatamente superior, los primeros referentes con los que se produjo la articulación fueron expertos especializados en estudios ecológicos. Los científicos en cuestión, pertenecientes a grupos de investigación de distintas universidades nacionales, realizan investigaciones en la zona desde la década del '90, y sus trabajos fueron utilizados como insumo para la formulación de un inventario preliminar ${ }^{8}$. Por lo tanto, inicialmente, los actores predominantes en la arena constituida en el nivel operacional eran principalmente funcionarios estatales, técnicos de campo, científicos y personal legislativo.

La estructura de esta arena, sin embargo, se vio profundamente afectada por un evento externo, un shock (Sabatier, 1991), derivado de una decisión de política tomada en el marco del subsistema de política forestal, que modificó sustantivamente qué actores participarían en él, así como las relaciones entre ellos. La Ley de Promoción Forestal, una norma nacional sancionada en 1998 y con una duración de diez años, otorgaba una serie de beneficios que fueron centrales para contribuir a la consolidación de la actividad forestal en el Delta Bonaerense (Fernández, 2016). Sin embargo, la prórroga sancionada en 2008 incluyó un artículo que especificaba que sólo se promovería la implantación de bosques cultivados en zonas que no estuvieran afectadas por el OTBN realizado en el marco de la "Ley de Bosques", para así evitar que la expansión de los bosques cultivados se produjera a través del desmonte de los bosques nativos. Esto tuvo como consecuencia directa que los productores forestales estarían imposibilitados de acceder a los beneficios de dicha ley hasta tanto no se sancionara la "Ley de Bosques", y contribuyó a que los actores vinculados con esta actividad en la provincia de Buenos Aires se convirtieran en los demandantes primarios de la construcción de un OTBN que les permitiera continuar con sus prácticas productivas. Por lo tanto, productores forestales, asociaciones de empresas, y funcionarios y técnicos de agencias de desarrollo rural y de promoción de la forestación emergerían como participantes centrales en este nivel ${ }^{9}$.

8 Dado que no es el foco de este trabajo, aquí no haremos mayor énfasis en esta cuestión. Para un análisis detallado de las técnicas de inventariado de los bosques nativos en el Delta Bonaerense, ver Straccia (2021).

9 Si bien ninguno de estos actores podría ser caracterizado como especialmente interesado en la protección del ambiente, tampoco tienen correlato con los sectores dominantes que en la mayor parte de las provincias están vinculados con la coalición productivista. En términos de Gutiérrez (2017): sus demandas, antes que con la expansión de la frontera agropecuaria, se asocian con continuar con sus prácticas de vida en sus lugares/ paisajes. 
De hecho, en agosto de 2011 se realizó una segunda reunión de referentes técnicos para la región Delta y Talares de Barranca con el fin de finalizar la construcción de un OTBN preliminar. Alí participaron tanto los expertos mencionados previamente como los representantes de agencias estatales vinculadas al desarrollo rural y técnicos de agencias estatales nacionales y provinciales vinculadas con la promoción de la forestación (OPDS, 2011). De esta forma, comenzaba a evidenciarse la participación de los actores del subsistema de política forestal en estos espacios, como resultado de la articulación entre la Ley de Promoción Forestal y la "Ley de Bosques".

En octubre de 2011, a fin de presentar el ordenamiento territorial preliminar de los bosques nativos de la región (el cual retomaba las investigaciones ecológicas realizadas y los ordenamientos municipales preexistentes), se realizó un Taller Participativo en el Delta Bonaerense del Paraná. En este encuentro más del $60 \%$ de los asistentes estaban vinculados a la producción forestal y al monocultivo de salicáceas, y allí tanto los productores forestales presentes como los técnicos de las agencias estatales vinculadas al desarrollo rural y a la promoción de la forestación se manifestaron abiertamente en contra de la propuesta de OTBN presentada (OPDS, 2011).

Como postula Oszlak (2006), cada agencia estatal compite por ganar posiciones dentro de un espacio de políticas, y en el proceso define su ámbito funcional de operación. En relación con la cuestión ambiental, lo propio es señalado por Gutiérrez (2017). En este sentido, la Zona Núcleo Forestal del Delta Bonaerense se ha constituido en las últimas décadas en un polo productivo en donde la presencia del Estado se hace visible a través de las agencias estatales vinculadas al desarrollo rural y la promoción de la forestación (Moreira, 2018), y la aparición de una nueva agencia estatal (en este caso vinculada a la protección del ambiente) podía verse como una amenaza para sus operatorias cotidianas. Esto puede ser considerado como uno de los elementos que favoreció la conformación de un actor colectivo que buscaba orientar la política pública en determinada dirección: actores individuales correspondientes a diferentes entidades presentaban creencias instrumentales similares y se involucraron en el proceso con un grado importante de coordinación (Sabatier, 1988; Sabatier y Weible, 2010).

En este caso, productores forestales individuales y agrupados, agencias estatales de desarrollo rural, funcionarios municipales y agencias estatales de promoción de la forestación operaron conjuntamente, cuestionando la metodología utilizada para inventariar los bosques nativos de la zona. El insumo principal se había producido a partir de la interpretación de secuencias de imágenes satelitales, y los diferentes miembros de la coalición cuestionaban que la fotointerpretación fuera válida y legítima en sí misma. 


\section{Patricio Hernán Straccia}

Así, la acción de "cargarlos en la lancha y llevarlos para que vean lo que tienen en la imagen", como lo recordaba uno de los técnicos que participó en esta instancia al ser entrevistado en noviembre de 2016, fue una estrategia ideada conjuntamente por estos actores. Y, a través de esta acción, se esperaba lograr como resultado la revisión del inventario existente y la construcción de uno nuevo en el que sus puntos de vista fueran tomados en cuenta.

A partir de la articulación entre los técnicos de la autoridad de aplicación provincial, los productores forestales con niveles elevados de capitalización y los funcionarios y técnicos de las agencias estatales vinculadas con el desarrollo rural y la promoción de la forestación se construyó la segunda propuesta de OTBN de la Región Delta y Talares de Barranca. Dicha propuesta presentaba una reducción sustantiva en la superficie de bosques nativos inventariada y un cambio en los niveles en que estos espacios eran categorizados respecto de la primera propuesta; los científicos cuyos insumos habían sido utilizados en la construcción de la primera propuesta manifestaron públicamente su rechazo a estos cambios, pero sus demandas no fueron atendidas (Straccia, 2021). Finalmente, en febrero de 2014 se realizó la Segunda Audiencia Pública provincial sobre la "Ley de Bosques", donde se presentó la propuesta definitiva de OTBN para el Delta Bonaerense y para las restantes regiones de la provincia. Allí, lógicamente, los representantes de las asociaciones de productores forestales y los funcionarios y técnicos de las agencias estatales de desarrollo rural y de promoción de la forestación manifestaron su apoyo a la propuesta presentada, y los funcionarios y técnicos de la autoridad de aplicación consideraron que el mapa "ya había sido consensuado".

Analizar el proceso de construcción del OTBN en la región Delta y Talares de Barranca en el nivel operacional supone identificar las variables exógenas que estructuran la arena de acción, de acuerdo con los elementos descriptores de la Tabla 1. Los modos de definición y delimitación de los bosques nativos, las actividades permitidas en cada categoría de zonificación o los mecanismos de participación (a través de audiencias públicas en el caso de la ciudadanía o a través de encuentros con referentes en el caso de los expertos), se configuraban como reglas externas que se habían constituido a otros niveles y estructuraban la arena de acción. En relación con las condiciones biofísicas y materiales, todos los actores coincidían en reconocer el grado de degradación de los bosques nativos de la zona y la importancia de preservar los relictos existentes, pero disentían en cuáles áreas eran bosque nativo y cuáles no. Asimismo, esta arena de acción estaba atravesada por la disputa entre los discursos de producción y conservación en torno a la definición de las formas de uso y apropiación del ambiente en el Delta Bonaerense del río Paraná (Straccia, 2019). Este contexto político, así como 
la articulación entre la "Ley de Bosques" y la Ley de Promoción Forestal previamente mencionada, favoreció configuraciones específicas de la arena de acción (es decir, definió los atributos de la comunidad), y contribuyó a que un conjunto específico de participantes (productores forestales con niveles elevados de capitalización y funcionarios y técnicos de agencias estatales vinculadas con el desarrollo rural y la promoción de la forestación) operaran colectivamente en pos de la consecución de sus respectivos intereses.

Analizar el proceso de construcción del OTBN en la región Delta y Talares de Barranca a un nivel operacional desde el marco del IAD también supone caracterizar la arena de acción a partir de los elementos descriptores indicados en la Tabla 1. Como se evidencia en este recorrido, el principal factor estructurante de la situación de acción se vinculó con cuáles eran los actores participantes. La construcción de una primera propuesta de OTBN que afectaba directamente zonas en las que hoy en día se desarrolla la actividad forestal y silvopastoril favoreció a que estos actores se erigieran como participantes centrales en la arena de acción. Por otro lado, y en los términos de Ostrom (2007), los resultados potenciales vinculados a las acciones individuales eran más limitados que si operaban colectivamente, mientras que las consecuencias de la producción de un OTBN que no les permitiera continuar con sus actividades productivas eran interpretadas por estos actores como una amenaza real para continuar con sus prácticas productivas y de vida en las islas. La conjunción de estos elementos, en una arena de acción donde ningún participante individual tenía un nivel de control marcadamente superior al de los restantes (como sí sucederá a nivel decisional, como veremos en el próximo apartado), favoreció: a) la articulación de los actores vinculados a la actividad forestal como una coalición con alto nivel de coordinación; y b) que este actor colectivo se erigiera como dominante en esta arena. De este modo, llevaron a cabo múltiples acciones a fin de influir sobre la política en una determinada dirección, cuestionando la legitimidad de la primera propuesta y construyendo mecanismos que les permitieron influir en la producción de una propuesta alternativa que pudiera ser presentada como consensuada por parte de la autoridad provincial de aplicación.

\section{El nivel decisional: la sanción de la "Ley de Bosques" en la provincia de Buenos Aires}

El ingreso formal del anteproyecto de "Ley de Bosques" se produjo a mediados de 2015. En septiembre de ese año, el proyecto de ley (con su correspondiente OTBN) fue aprobado por la Cámara de Senadores de la 
provincia de Buenos Aires sin mediar mayor discusión y fue enviado a la Cámara de Diputados provincial. Dicha Cámara lo derivó a la Comisión de Ecología y Medio Ambiente en primera instancia y a la Comisión de Asuntos Agrarios de forma complementaria. Ambas comisiones debían emitir despacho, y a partir de ello los diputados podrían sancionar (o rechazar) la "Ley de Bosques". Dado que el ingreso se produjo en el período legislativo 2015, este proyecto debía ser tratado antes del cierre del 2016 a fin de evitar que perdiera estado parlamentario.

La arena de acción en el nivel decisional estaba estructurada de un modo radicalmente distinto al de las arenas en el nivel operacional. Esto no sólo tenía que ver con el nuevo ámbito geográfico en el que se dirimían las disputas (focalizadas ahora en la capital provincial), sino por sobre todas las cosas por la diferencia en los actores participantes en la arena de acción y en las posiciones que ocupaban cada uno de ellos. Más específicamente, la coalición forestal, que en tanto actor colectivo había logrado influir de modo decisivo en la construcción del OTBN de la región Delta y Talares de Barranca, continuó operando como tal pero no ocupó espacios centrales en este nivel decisional. Y es que la "Ley de Bosques", en otras zonas de la provincia como la región Bosques Ribereños, podía afectar los intereses de actores con mucha mayor capacidad de controlar el proceso político.

De acuerdo con quienes tenían acceso a estos espacios de decisión, la presión ejercida por los desarrolladores inmobiliarios es lo que generó las demoras en la sanción de la "Ley de Bosques". En particular, el emprendimiento Nueva Costa del Plata, que sería desarrollado por Techint en la franja costera de Quilmes-Avellaneda (Aizcorbe et al., 2013; Santy, 2014; Calefato, 2018), fue señalado como el principal factor de conflicto en relación con el OTBN provincial construido: allí, una multiplicidad de actores estatales y no estatales disputaban en torno a cuáles eran los usos que debían darse a la zona costera de estos partidos (Santy, 2019). Techint es una empresa transnacional con gran capacidad de lobby y llegada directa a las esferas superiores municipales, provinciales y nacionales, de modo que podría ser descripto como un participante con muy altos niveles de control sobre aquello que está en disputa, en los términos del IAD. Según uno de los diputados de esta Comisión, los legisladores de los distintos partidos políticos carecían de mandato a la hora de votar, y tratándose de una arena de acción caracterizada por la presencia de un actor con fuertes conexiones políticas a múltiples niveles, preferían ausentarse de la reunión y no brindar quórum. En otras palabras, dos variables exógenas (los atributos de la comunidad y el contexto político) eran sumamente diferentes al nivel decisional en relación con el nivel operacional, y propiciaban una configuración singular de esta arena de acción. 
Para entender de qué forma finalmente se logró sancionar la "Ley de Bosques" en la provincia de Buenos Aires, es necesario comprender los cambios en la estructura de oportunidades políticas (Koopmans y Statham, 2000) producidos luego de las elecciones generales que se llevaron a cabo en la provincia y en el país en el año 2015. Luego de la victoria de la coalición Cambiemos en ambos niveles, el nuevo gobierno nacional elevó el rango de la Dirección de Producción Forestal (reconvertida en Subsecretaría de Desarrollo Forestoindustrial) y prácticamente triplicó el presupuesto destinado a la Ley de Promoción Forestal. De esta forma, se produjo un cambio en la estructura de oportunidades políticas, especialmente en su dimensión institucional (Koopmans, 2004).

Simultáneamente, los vínculos entre los actores fueron reconstruidos en un nuevo contexto político que permitió que algunos de ellos pudieran llevar adelante negociaciones personales con los legisladores bonaerenses. Así, emergió como figura clave un funcionario de una agencia estatal cuya misión es operar como articuladora de las políticas públicas municipales y provinciales en el Delta Bonaerense, y cuya asunción se había dado con el cambio de coalición gobernante. Este funcionario, que trabajaba desde hacía muchos años en el Delta Bonaerense, poseía una importante dotación de capital social y detentaba ahora una mayor dotación de capital político (Joignant, 2012), dado que su nuevo cargo le permitía acceder a nuevos espacios y ampliaba sustantivamente su capacidad de acción.

Los cambios en la estructura política, como señalan McAdam et al. (1999) facilitan la apertura de ventanas de oportunidades (Tarrow, 1994). En este caso, el funcionario en cuestión, desde su nuevo cargo, logró convocar al presidente de la Comisión de Ecología y Medio Ambiente a una reunión. Este encuentro se produjo en la segunda mitad de 2016, y al mismo asistieron también otros actores estrechamente vinculados con la actividad forestal en la zona del Delta del Paraná. Allí explicaron cuáles eran las consecuencias para el sector de la falta de sanción de la "Ley de Bosques", y diseñaron una estrategia conjunta: en primer lugar, realizarían la siguiente reunión de la Comisión de Ecología y Medio Ambiente, a desarrollarse en octubre de 2016, en el Delta del Paraná; complementariamente, también realizarían una visita a productores de la región. Así, estos actores diseñaron una estrategia que les permitió reposicionarse en esta arena de acción y operar en el contexto de una nueva estructura política.

Esta situación es uno de los elementos que explica por qué en este artículo utilizamos una versión adaptada del IAD, la versión "politizada" (Clement, 2010). Para el proceso de institucionalización de la "Ley de Bosques", el contexto político-económico es una variable exógena sumamente relevante, puesto que no sólo influyó sobre el comportamiento de los parti- 
cipantes, sino que, además, permite entender cómo procesos del pasado (en este caso, articulaciones entre actores) se reconstituyeron en el presente de la acción (Whaley y Weatherhead, 2014).

Luego de estos encuentros, el 22 de noviembre de 2016 se realizó una audiencia abierta convocada conjuntamente por las Comisiones de Ecología y de Asuntos Agrarios de la Cámara de Diputados de la provincia de Buenos Aires. Allí, todos los oradores vinculados con la actividad forestal y silvopastoril presentaron diversos argumentos para manifestar su apoyo al proyecto de ley bajo debate. En este nuevo nivel, en el que los recursos del sector forestal eran menores que los recursos que poseían otros actores participantes de la arena, la construcción discursiva de quiénes serían los afectados por la falta de sanción de la "Ley de Bosques" fue la principal herramienta que permitió legitimar su posterior aprobación.

Los productores forestales que intervinieron como oradores en la audiencia abierta destacaban su nivel de representatividad respecto del colectivo "isleños", en tanto categoría local que refiere a los nacidos y criados en la zona, y lograron imponer la categoría "isleños" articulada a través de una cadena equivalencial que la vinculaba con pequeños productores, con lugareños, con pobladores aislados del continente y de la ciudad (Straccia, 2019). En este nuevo escenario, la categoría "pequeño" (productor isleño) se constituyó en relación con un otro más grande/poderoso (los megaemprendimientos inmobiliarios). Sin embargo, esto no debe entenderse como una relación de antagonismo entre dos actores a partir de intereses contrapuestos, sino más bien como el desarrollo de una estrategia colectiva que buscaba posicionar a este sector como un colectivo afectado por la falta de sanción de la Ley y cuyas demandas debían ser satisfechas por los legisladores.

Como señala Angenot (2010), la imposición de ciertas categorías en estas instancias es una parte central de las disputas políticas. En esta nueva configuración de la arena de acción, la imposición de la categoría "pequeños productores isleños" puede ser interpretada como una estrategia discursiva de aquellos que aseguraban representar a todos los "isleños" en esta audiencia ${ }^{10}$. De hecho, en una entrevista tras la finalización de la au-

\footnotetext{
10 Señalemos, sin embargo, que esto no debe interpretarse como una acción social racional con arreglo a fines, en su sentido weberiano. Como señala Clement (2010) en su discusión sobre los enfoques racionalistas en general y sobre el IAD en particular, la intencionalidad de los actores es reconocida pero sus estrategias están atravesadas por los sistemas culturales y estructurales en las que se desarrollan. En otras palabras, sus estrategias no dependen únicamente de las posiciones que ocupan ni de sus trayectorias individuales, sino también de los habitus incorporados. Por ello, los participantes no necesariamente sabrán consciente y racionalmente qué hacen o para qué, ni necesitarán plantearse explícitamente el problema para saber cómo actuar.
} 
diencia, uno de los diputados provinciales fundó su apoyo y el de su bloque a la sanción de la Ley en el hecho de que "no queremos perjudicar a estos pequeños productores isleños". Lo mostrado aquí también ayuda a comprender por qué el IAD "politizado" es un marco conceptual apropiado para este objeto de estudio: las posiciones que ocupan los actores no representan únicamente sus inserciones en espacios predefinidos (esto es, roles), sino que se evidencia cómo éstos construyen sus propias posiciones a través de conceptos y categorías relacionadas con narrativas particulares (Whaley y Weatherhead, 2014).

Por su parte, los legisladores retomaron estos argumentos para legitimar la sanción de la "Ley de Bosques". A fines de noviembre ambas comisiones se expidieron favorablemente al proyecto, y los diputados firmantes hicieron especial énfasis en señalar las consecuencias que la demora en su sanción había tenido sobre el sector forestal y los pobladores de "la isla". En términos de los resultados de la acción, la postura de los legisladores resultó ser favorable a los intereses de los desarrolladores inmobiliarios de la zona Quilmes-Avellaneda. Como indicamos previamente, la presión ejercida por estos actores era lo que había generado las demoras en la sanción de la "Ley de Bosques", y recién dejaron de presionar activamente una vez que se aseguraron de que el ordenamiento propuesto les permitiría continuar con sus emprendimientos.

Según Santy (2019), las categorías de conservación de los bosques nativos comprendidos en el OTBN en el área de los bosques ribereños se habrían degradado a fin de que la OPDS pudiera brindar la habilitación ambiental correspondiente al Nueva Costa del Plata. En ese sentido, no es extraño que los argumentos de los legisladores para justificar su posición favorable a la Ley no hicieran referencia a estas cuestiones, y que reseñaran únicamente los impactos que la falta de sanción de dicha ley generaría sobre los "pequeños productores isleños".

De hecho, el OTBN propuesto por la autoridad de aplicación no limitó ni restringió el desarrollo de Nueva Costa del Plata (Santy, 2019), haciendo evidente que los actores vinculados con el desarrollo de emprendimientos inmobiliarios ocupaban una posición dominante en esta arena de acción y llevaron adelante una estrategia hegemónica en el nivel decisional. Esto es, se trató de una estrategia que incorporó parcialmente las demandas de otros sectores (los productores forestales del Delta del Paraná), pero desarticuladas de su propio contexto de producción, y por lo tanto las integró hegemónicamente (Balsa, 2011). En cambio, los discursos de injusticia ambiental (Calefato, 2018), activados por actores individuales y colectivos con menor capacidad de ejercicio de poder en esta arena de acción (como 
vecinos afectados u organizaciones socioambientales), no lograron instituirse en este nivel decisional.

Finalmente, a partir del dictamen conjunto de ambas comisiones recomendando su aprobación, el proyecto de Ley fue elevado a la Cámara de Diputados de la Provincia de Buenos Aires. En una sesión extraordinaria, el 21 de diciembre de 2016 la Cámara aprobó la "Ley de Bosques" junto con su OTBN correspondiente. Y en agosto de 2017 se sancionó el decreto reglamentario necesario para instrumentalizar los diferentes artículos de la Ley.

\section{Conclusiones}

En este artículo se analizó el proceso de institucionalización de la "Ley de Bosques”, una política pública en materia ambiental de la provincia de Buenos Aires. A partir de una norma nacional (la Ley 26.331 de Protección Ambiental de los Bosques Nativos) se constituyeron múltiples arenas de acción a diferentes niveles (decisional y operacional) en los que diferentes actores purgaron por orientar la política en una u otra dirección.

En la región Delta y Talares de Barranca, una de las cuatro arenas de acción constituidas a nivel operacional, la configuración inicial de la arena se vio profundamente afectada a partir de las modificatorias en la prórroga de la Ley de Promoción Forestal, un evento externo derivado de una decisión de política tomada en el marco del subsistema de política forestal, que modificó cuáles serían los actores participantes y la configuración de la arena de acción. A partir del análisis de los registros etnográficos y de los documentos producidos por las agencias estatales, mostramos que los múltiples actores vinculados con la actividad forestal formaron una coalición con alto nivel de coordinación en esta arena de acción, y diseñaron estrategias de acción conjunta. Esta coordinación les permitió lograr un resultado (en este caso, un OTBN) acorde a su estructura de preferencias, esto es, a sus diferentes intereses específicos.

En el nivel decisional, por su parte, la arena de acción constituida presentaba una configuración radicalmente diferente, con otros participantes y otros recursos. En primer lugar, se mostró que la mencionada coalición carecía de la capacidad de influencia que poseía en el nivel operacional, y se evidenció que eran actores vinculados al desarrollo de emprendimientos inmobiliarios, con mayores recursos económicos y políticos, quienes ocupaban una posición dominante en esta arena. En segundo lugar, señalamos que los cambios en la estructura de oportunidades políticas favorecieron la 
apertura de una ventana de oportunidad, que cambió la distribución de los recursos y permitió que estos actores pudieran acceder a nuevos espacios que previamente les estaban vedados. Y se mostró cómo, a partir de dichos cambios, este conjunto de actores llevó adelante nuevas estrategias que sí les permitieron construir una posición en línea con sus intereses y capaz de influir en la producción de la política pública, así como brindar las herramientas necesarias para legitimar una decisión favorable por parte de los legisladores provinciales.

De este modo, desde una perspectiva metodológica cualitativa conceptualmente articulada con el marco de análisis del IAD "politizado", se realiza un aporte al campo de estudios de las políticas públicas y se evidencia que éstas son el resultado de disputas y negociaciones entre múltiples actores estatales y no estatales. Complementariamente, el foco en las diversas estrategias desarrolladas por los diferentes actores permitió resaltar algunas de las formas a través de las cuales se producen las estatalidades, y mostrar cómo las variables exógenas propuestas por Clement (2010) operan en el proceso de formulación de las políticas.

Este análisis, por su parte, se vería sumamente enriquecido por futuros estudios que analicen las restantes arenas de acción constituidas en el nivel operacional, especialmente en la Región Bosques Ribereños. Santy (2019) menciona que la "Ley de Bosques" fue conocida en los medios regionales como la "Ley Techint", por lo favorable que resultó el OTBN propuesto para sus proyectos inmobiliarios. Por lo tanto, estudios que articulen estos conflictos con la producción del OTBN en la Región Bosques Ribereños desde el marco del IAD serían sumamente relevantes para indagar con más profundidad sobre los modos en que se produce la interrelación entre: a) distintas arenas de acción constituidas a un mismo nivel (en este caso, el nivel operacional); y b) arenas de acción constituidas a diferentes niveles (arenas múltiples constituidas a nivel operacional y una única arena constituida a nivel decisional), puesto que allí radica la principal fortaleza de este marco conceptual (Jaime et al., 2013). Además, a partir de este trabajo, futuros escritos podrán articularse con otros elementos teóricos para desarrollar con mayor nivel de detalle lo ocurrido en cada una de las diferentes instancias, y focalizar en las formas en las que los funcionarios y los técnicos de las diferentes agencias estatales participantes en el proceso, es decir, los empleados de base (Lipsky, 1996), operaron en el proceso de producción de la política pública. 


\section{Patricio Hernán Straccia}

\section{Referencias bibliográficas}

Aguiar, S., Mastrangelo, M., García Collazo, M. A., Camba Sans, G., Mosso, C., Ciuffoli, L., Schmidt, M., Vallejos, M., Langbehn, L., Cáceres, D., Merlinsky, G., Paruelo, J., Seghezzo, L., Staiano, L., Texeira, M., Volante, J. y Verón, S. (2018). ¿Cuál es la situación de la Ley de Bosques en la Región Chaqueña a diez años de su sanción? Revisar su pasado para discutir su futuro. Ecología Austral, $28,400-417$.

Aguilar Villanueva, L. F. (1992). El estudio de las políticas públicas. Distrito Federal, México: Porrúa.

Aguilar Villanueva, L. F. (1996). La hechura de las políticas. Distrito Federal, México: Porrúa.

Aizcorbe, M., Fernández Bouzo, S., \& Wertheimer, M. (2013). "Moros en la costa". Ambiente, actores locales y conicto en torno a los megaproyectos de urbanización sobre la franja costera de los partidos de Avellaneda, Quilmes y Vicente López (2000-2011). En G. Merlinsky (Ed.), Cartografias del conflicto ambiental en Argentina (pp. 173-199). Buenos Aires: Fundación CICCUS.

Angenot, M. (2010). El discurso social. Los límites históricos de lo pensable y lo decible. Buenos Aires: Siglo XXI Editores.

Araral, E., y Amri, M. (2016). «Institutions and the Policy Process 2.0: Implications of the IAD Framework». En G. Peters \& P. Zittoun (Eds.), Contemporary Approaches to Public Policy: Theories, Controversies and Perspectives (pp. 73-93). Londres: Palgrave Macmillan.

Astelarra, S., y Domínguez, D. (2015). Los junqueros de las islas del Delta del Paraná: sujetos emergentes en un territorio amenazado. Estudios Socioterritoriales. Revista de Geografia, 17(ene-jun), 129-162.

Baigún, C. (2013). Manual para la gestión ambiental de la pesca artesanal y buenas prácticas pesqueras en la cuenca del río Paraná, Argentina. Buenos Aires: Fundación para la Conservación y el Uso Sustentable de los Humedales.

Balsa, J. (2011). Aspectos discursivos de la construcción de la hegemonía. Identidades, $1(1), 70-90$.

Calefato, N. (2018). Transformaciones ambientales e (in)justicia espacial: el caso de la ribera de Quilmes y Avellaneda (Tesis de Licenciatura). Facultad de Agronomía, Universidad de Buenos Aires, Argentina.

Clement, F. (2010). Analysing decentralised natural resource governance: proposition for a «politicised» institutional analysis and development framework. Policy Sciences 43(2), 129-156.

Cowan Ros, C. (2016). Estatalidades politicas publicas y movimientos sociales en su configuración interdependiente. Una perspectiva analítica. Revista Científica Contested Cities - Working Paper Series. 
Díaz, M. d. V. (2006). La política ambiental argentina: su errático desarrollo. KAIROS. Revista de Temas Sociales, 10(18), 1-15.

Esain, J. A. (2004). El federalismo ambiental. Reparto de competencias legislativas en materia ambiental en la Constitución Nacional y la Ley General del Ambiente 25.675. Jurisprudencia Argentina 2004-I-776.

Escolar, C. (2000). «La recuperación del Análisis Institucional como perspectiva teórico-metodológica». En C. Escolar (Ed.), Topografias de la investigación. Métodos, espacios y prácticas profesionales (pp. 29-47). Buenos Aires: Eudeba.

Escolar, C. (2010). Institución, implicación, intervención. Revisando y revisitando las categorías del análisis institucional. Acciones e Investigaciones Sociales, 28, 235250.

Fernández, S. (2016). La política forestal en Argentina y su contribución a las transformaciones en el Delta del Paraná (Tesis de Licenciatura). Facultad de Agronomía, Universidad de Buenos Aires, Argentina.

García Collazo, M. A., Panizza, A., y Paruelo, J. (2013). Ordenamiento Territorial de Bosques Nativos: Resultados de la zonificación realizada por provincias del Norte argentino. Ecología Austral, 23, 97-107.

Gautreau, P., Langbehn, L., y Ruoso, L.-E. (2014). Movilización de información en el Ordenamiento Territorial de Bosques Nativos de Argentina: la heterogeneidad de los mapeos provinciales y la institucionalización de la problemática ambiental. En III Jornadas Nacionales de Investigación y Docencia en Geografía Argentina, UNC Tandil, Buenos Aires.

Guber, R. (2001). La etnografia. Método, campo y reflexividad (1 ed.). Buenos Aires: Ed. Norma.

Gutiérrez, R. (2017). La confrontación de coaliciones sociedad-estado: la política de protección de bosques nativos en Argentina (2004-2015). Revista SAAP, 11(2), 283-312.

Gutiérrez, R., y Isuani, F. (2013). Luces y sombras de la política ambiental argentina entre 1983 y 2013. Revista SAAP (Sociedad Argentina de Analísis Político), 7(2), 317328.

Gutiérrez, R., y Isuani, F. (2014). La emergencia del ambientalismo estatal y social en Argentina. Revista de Administração Pública (RAP), 48(2), 295-322.

Hammersley, M., y Atkinson, P. (2007). Ethnography: principles in practice (3rd Ed.). Reino Unido: Taylor \& Francis e-Library.

Instituto Nacional del Agua. (2018). Delta del Paraná. Proyectos estratégicos para el desarrollo sustentable. Buenos Aires: Secretaría de Infraestructura y Política Hídrica, Instituto Nacional del Agua.

Isuani, F. (2013). Institucionalidad ambiental en la provincia de Buenos Aires (1983-2011). Desafios a la coherencia, integralidad y coordinación. En VII Congreso Argentino de Administración Pública «Liderazgo, equidad y sustentabilidad», Mendoza. 
Jaime, F., Dufour, G., Alessandro M. y Amaya, P. (2013). Introducción al análisis de las políticas públicas. Florencio Varela: Universidad Nacional Arturo Jauretche.

Joignant, A. (2012). Habitus, campo y capital. Elementos para una teoría general del capital político. Revista Mexicana de Sociología, 74(4), 587-618.

Juliá, M. (2010). La ley de protección del bosque nativo en Argentina: algunos impactos jurídicos e institucionales del proceso de implementación. Pampa, 6, 169-185.

Koopmans, R. (2004). Migrant mobilisation and political opportunities: variation among German cities and a comparison with the United Kingdom and the Netherlands. Journal of Ethnic and Migration Studies, 30(3), 449-470.

Koopmans, R., y Statham, P. (2000). Migration and ethnic relations as a field of political contention: an opportunity structure approach. En R. Koopmans \& P. Statham (Eds.), Challenging Immigration and Ethnic Relations Politics. Comparative European Perspectives (pp. 14-56). Oxford: Oxford University Press.

Langbehn, L. (2016). «Arenas públicas, modelos de desarrollo y políticas de protección del ambiente: la Ley de Bosques entre 'conservación» $\mathrm{y}$ "producción'». En G. Merlinsky (Ed.), Cartografias del conflicto ambiental 2 (pp. 141-168). Buenos Aires: Fundación CICCUS.

Lipsky, M. (1996). Los empleados de base en la elaboración de políticas públicas. En J. Brugué y J. Subirats (Eds.), Lecturas de Gestión Pública (pp. 279-298). Madrid: Instituto Nacional de Administración Pública (INAP).

Mason, J. (2002). Qualitative Researching. Londres: Sage.

McAdam, D., McCarthy, J., y Zald, M. (1999). «Oportunidades, estructuras de movilización y procesos enmarcadores: hacia una perspectiva sintética y comparada de los movimientos sociales». En D. McAdam, J. McCarthy y M. Zald (Eds.), Movimientos sociales: perspectivas comparadas (pp. 21-46). Madrid: Istmo.

Melé, P. (2003). «Introduction: conflits, territoires et action publique». En P. Melé, C. Larrue y M. Rosemberg (Eds.), Conflits et territoires (pp. 224). Tours: Presses universitaires Francois-Rabelais.

Merlinsky, G. (2013). Cartografias del conflicto ambiental en Argentina. Buenos Aires: Fundación CICCUS.

Moreira, C. J. (2018). La institucionalización del desarrollo rural en los procesos de innovación tecnológica de manejo del agua en la Zona Núcleo Forestal del Delta del Paraná (Tesis de Maestría). FLACSO, Buenos Aires, Argentina.

Müller, P. (2000). Elementos para una estrategia de investigación sobre políticas públicas. Innovar. Revista de ciencias administrativas y sociales, 16, 49-54.

Olemberg, D., y Barán, S. (2017). El mimbre en el Delta. Resultados del censo de productores mimbreros año 2015. Buenos Aires: INTA Ediciones.

Ostrom, E. (2005). Understanding Institutional Diversity. Princeton: Princeton University Press. 
Ostrom, E. (2007). «Institutional Rational Choice: an assessment of the Institutional Analysis and Development Framework». En P. Sabatier (Ed.), Theories of Policy Process (pp. 23-74). Boulder, Estados Unidos: Westview Press.

Oszlak, O. (2006). Burocracia estatal: política y políticas públicas. POSTData Revista de Reflexión y Análisis Político, 11(4), 1-30.

Penalva Verdú, C., Alaminos Chica, A., Francés García, F. J., y Santacreu Fernández, Ó. A. (2015). La investigación cualitativa: técnicas de investigación y análisis con Atlas.Ti. Cuenca, Ecuador: PYDLOS Ediciones.

Piermattei, S. (2013). Local farmers vs environmental universalism: Conflicts over nature conservation in the Parco Nazionale dei Monte Sibillini, Italy.Journal of Political Ecology, 20, 306-317.

Pizarro, C. (2016). «Trabajadores paraguayos en la producción forestal del Delta Inferior del río Paraná». En S. Aparicio y R. Benencia (Eds.), De migrantes y asentados. Trabajo estacional en el agro argentino (pp. 115-138). Buenos Aires: Fundación CICCUS.

Pizarro, C., y Ortiz, D. (2019). «Vivir (después de) la inundación en «la Isla». Las experiencias de «su» paisaje de los habitantes de la Zona Núcleo Forestal». En C. Pizarro (Ed.), «Nosotros creamos el Delta». Habitar, forestar y conservar un humedal (pp. 161-182). Buenos Aires: Fundación CICCUS.

Portes, A. (2006). Instituciones y desarrollo: una revisión conceptual. Cuadernos de Economía, 25(45), 13-52.

Quintana, R. D., Bó, R., Astrada, E., y Reeves, C. (2014). Lineamientos para una ganadería ambientalmente sustentable en el Delta del Paraná. Buenos Aires: Fundación Humedales.

Roig, A. (2008). El desarrollo como conflicto institucionalizado. Realidad Económica, 237, 80-92.

Sabatier, P. (1988). An advocacy coalition framework of policy change and the role of policy-oriented learning therein. Policy Sciences, 21, 129-168.

Sabatier, P. (1991). Toward Better Theories of the Policy Process. Policy Science E Politics, 24(2), 147-156.

Sabatier, P., y Weible, C. (2010). «El marco de las coaliciones promotoras. Innovaciones y clarificaciones». En P. Sabatier (Ed.), Teorías del proceso de las políticas públicas (pp. 203-238). Buenos Aires: Jefatura de Gabinete de Ministros.

Santy, V. (2014). Nueva Costa del Plata: las formas de la legitimación y la resistencia en un conflicto socio-ambiental del sur del Conurbano bonaerense (Tesis de Maestría), Buenos Aires, Argentina.

Santy, V. (2019). Caso Nueva Costa del Plata: conflicto, espacialización y territorialización en Avellaneda y Quilmes. Geograficando, 15(2).

Schmidt, M. (2014). «Ordenadores y ordenados». Actores en disputa en el ordenamiento territorial de bosques nativos en la provincia de Salta. Cuadernos de Antropología, 11, 37-55. 
Shore, C., y Wright, S. (1997). Anthropology of Policy. Critical perspectives on governance and power. London: Routledge.

Silverman, D. (2000). Doing Qualitative Research: A Practical Handbook. Thousand Oaks, CA: Sage.

Silvetti, F., Soto, G., Cáceres, D., y Cabrol, D. (2013). ¿Por qué la legislación no protege los bosques nativos de Argentina? Conflictos socioambientales y políticas públicas. Mundo Agrario, 13(26), 1-21.

Stecher, G. A. (2013). Ley de Bosques. Su aplicación en territorios de comunidades campesinas e indígenas en la Provincia de Neuquén. Nuevos modos de exclusión. En VII Jornadas Santiago Wallace de Investigación en Antropología Social, ICA - FFyL UBA.

Straccia, P. (2019). «Esto lo tenemos que solucionar desde adentro». El uso político de la identidad 'isleña' en un área del Delta del río Paraná en los procesos de institucionalización de leyes ambientales (Tesis de Maestría). Facultad de Filosofía y Letras, Universidad de Buenos Aires, Argentina.

Straccia, P. (2021). Disputas en la producción del Ordenamiento Territorial de Bosques Nativos ("Ley de Bosques") en el Delta Bonaerense del río Paraná. RUNA. Archivo Para Las Ciencias Del Hombre, 42(1), 369-390.

Subirats, J., Knoeppel, P., Larrue, C., y Varone, F. (2008). Análisis y gestión de políticas públicas. Barcelona: Ariel.

Tarrow, S. (1994). Power in movement. Social movements, collective action and politics. Cambridge: Cambridge University Press.

Taylor, S., y Bogdan, R. (1996). Introducción a los métodos cualitativos de investigación. Buenos Aires: Ed. Paidós.

Vera, A. (2015). «El primer ordenamiento territorial de bosques nativos de Córdoba: Algunos aspectos políticos e institucionales del proceso participativo». En M. Juliá (Ed.), La investigación jurídica en políticas públicas ambientales. Parte II (pp. 211-231). Córdoba: Advocatus.

Whaley, L. y Weatherhead, E. (2014). An Integrated Approach to Analyzing (Adaptive) Comanagement Using the "Politicized" IAD Framework. Ecology and Society 19(1), 10.

Wedel, J., Shore, C., Feldman, G., y Lathrop, S. (2005). Toward an anthropology of public policy. Annals of the American Academy of Political and Social Science, 600, 30-51.

\section{Fuentes Secundarias}

Ley Nacional 25.080. “Ley de Inversiones para Bosques Cultivados”. Disponible online en http://servicios.infoleg.gob.ar/infolegInternet/verNorma.do?id=55596 [Consultada por última vez el 6/7/2018] 
Ley Nacional 26.331. "Ley de Presupuestos Mínimos para la Protección Ambiental de los Bosques Nativos". Disponible online [consultada por última vez el 6/7/ 2018] en http://servicios.infoleg.gob.ar/infolegInternet/verNorma.do?id=136125

Ley Nacional 26.432. "Ley de Inversiones para Bosques Cultivados". Disponible online en http://servicios.infoleg.gob.ar/infolegInternet/verNorma.do?id=148753 [Consultada por última vez el 6/7/2018]

Ley Provincial 14.888. "Normas complementarias para la conservación y el manejo sostenible de los bosques nativos de la provincia de Buenos Aires". Disponible online en http://www.gob.gba.gov.ar/legislacion/legislacion/l-14888.html [consultada por última vez el 6/7/2018]

Ley Provincial 14.888. Decreto reglamentario 366/2017. Disponible online en http:/ /www.gob.gba.gov.ar/legislacion/legislacion/17-e-366.html [consultada por última vez el 6/7/2018]

MAyDS. (2016). Ley $N^{\circ} 26331$ de presupuestos mínimos de protección ambiental de los bosques nativos: informe de estado de implementación 2010-2015.

OPDS. (2011). Taller participativo de información y consulta sobre el Ordenamiento Territorial de los Bosques Nativos de la Provincia de Buenos Aires (pp. 103). Buenos Aires, Argentina: Organismo Provincial para el Desarrollo Sostenible, Gobierno de la Provincia de Buenos Aires.

OPDS. (2013). Informe de las actuaciones desarrolladas por el Organismo Provincial para el Desarrollo Sostenible (OPDS) en el marco de la Ley Nacional 26331 de Presupuestos Mínimos de Protección Ambiental de los Bosques Nativos. La Plata, Buenos Aires: Organismo Provincial para el Desarrollo Sostenible.

SAyDS. (2005). Primer Inventario Nacional de Bosques Nativos. Informe Nacional. 


\section{Patricio Hernán Straccia}

\section{Anexo Metodológico}

\section{Entrevistas Realizadas}

Para la producción de datos primarios, se realizaron entrevistas con 91 personas. Entrevistamos a productores y pobladores de la Zona Núcleo Forestal del Delta Bonaerense del río Paraná: siguiendo la tipología propuesta por Pizarro (2016), entrevistamos a pequeños productores familiares, productores familiares capitalizados, productores familiares empresariales y representantes de empresas forestoindustriales. Además, entrevistamos a funcionarios y técnicos del Instituto Nacional de Tecnología Agropecuaria, funcionarios y técnicos de la Dirección Nacional Forestal (Ministerio de Agricultura, Ganadería y Pesca de la Nación), funcionarios y técnicos de Bosques y Forestación (Ministerio de Desarrollo Agrario de la Provincia de Buenos Aires), técnicos de la Dirección Provincial de Islas de la Provincia de Buenos Aires, funcionarios y técnicos de la Dirección Nacional de Bosques (Ministerio de Ambiente y Desarrollo Sostenible de la Nación), funcionarios y técnicos del Organismo Provincial para el Desarrollo Sostenible de la Provincia de Buenos Aires y referentes técnicos para la región 'Delta y Talares de Barranca'. Cabe señalar que algunas entrevistas fueron colectivas y otras individuales, y que en varias ocasiones llevamos adelante más de un encuentro con el o los mismos entrevistados.

\section{Instancias de Observación Participante}

Se incluyeron en el corpus un total de 36 registros de instancias de observación participante. Estos registros fueron producidos en el evento anual denominado ‘Día del Isleño' (desde el año 2012 en adelante), el ‘Encuentro Isleño’ realizado en 2015, reuniones de organizaciones locales, reuniones organizadas por el Instituto Nacional de Tecnología Agropecuaria, la Audiencia Abierta realizada en La Plata en noviembre de 2016 en relación con la "Ley de Bosques", el IV Congreso Internacional de Salicáceas organizado por la Comisión Nacional del Álamo en Argentina, y encuentros organizados por Fundación Humedales y otras organizaciones ambientales vinculadas con la protección de los humedales del Delta del Paraná. 